\title{
Protective cellular and mucosal immune responses following nasal administration of a whole gamma-irradiated influenza $A$ (subtype H1N1) vaccine adjuvanted with interleukin-28B in a mouse model
}

\author{
Ailar Sabbaghi ${ }^{1} \cdot$ Mohsen Zargar $^{1}$ (D) Mohammad Reza Zolfaghari ${ }^{1} \cdot$ Farahnaz Motamedi-Sedeh $^{2} \cdot$ Amir Ghaemi $^{3}$ (I)
}

Received: 16 June 2020 / Accepted: 14 October 2020 / Published online: 6 January 2021

(c) Springer-Verlag GmbH Austria, part of Springer Nature 2021

\begin{abstract}
The use of gamma-irradiated influenza A virus ( $\gamma$-Flu), retains most of the viral structural antigens, represent a promising option for vaccine development. However, despite the high effectiveness of $\gamma$-Flu vaccines, the need to incorporate an adjuvant to improve vaccine-mediated protection seems inevitable. Here, we examined the protective efficacy of an intranasal gamma-irradiated HIN1 vaccine co-administered with a plasmid encoding mouse interleukin-28B (mIL-28B) as a novel adjuvant in BALB/c mice. Animals were immunized intranasally three times at one-week intervals with $\gamma$-Flu, alone or in combination with the mIL-28B adjuvant, followed by viral challenge with a high lethal dose $\left(10 \mathrm{LD}_{50}\right)$ of A/PR/8/34 (H1N1) influenza virus. Virus-specific antibody, cellular and mucosal responses, and the balance of cytokines in the spleen IFN- $\gamma$, IL-12, and IL-4) and in lung homogenates (IL-6 and IL-10) were measured by ELISA. The lymphoproliferative activity of restimulated spleen cells was also determined by MTT assay. Furthermore, virus production in the lungs of infected mice was estimated using the Madin-Darby canine kidney (MDCK)/hemagglutination assay (HA). Our data showed that intranasal immunization with adjuvanted $\gamma$-Flu vaccine efficiently promoted humoral, cellular, and mucosal immune responses and efficiently decreased lung virus titers, all of which are associated with protection against challenge. This combination also reduced IL-6 and IL-10 levels in lung homogenates. The results suggest that IL-28B can enhance the ability of the vaccine to elicit virus-specific immune responses and could potentially be used as an effective adjuvant.
\end{abstract}

\begin{tabular}{ll}
\multicolumn{2}{l}{ Abbreviations } \\
$\gamma$-Flu & Gamma-irradiated influenza A virus \\
IFNs & Interferons \\
IFN- $\lambda$ & Interferon lambda \\
IL-28B & Interleukin-28B \\
HSV-2 & Herpes simplex virus type 2 \\
HIV & Human immunodeficiency virus \\
MDCK & Madin-Darby canine kidney
\end{tabular}

Handling Editor: William G Dundon.

Mohsen Zargar

zmohsen2002@yahoo.com; zargar@qom-iau.ac.ir

Amir Ghaemi

ghaem_amir@yahoo.com; a_ghaemi@pasteur.ac.ir

1 Department of Microbiology, Qom Branch, Islamic Azad University, P.O. Box: 374911319, Qom, Iran

2 Nuclear Agriculture research school, Nuclear Science and Technology Research Institute, Atomic Energy Organization of Iran, Karaj, Iran

3 Department of Influenza and Other Respiratory Viruses, Pasteur Institute of Iran, P.O. Box: 1316943551, Tehran, Iran

$\begin{array}{ll}\text { MOI } & \text { Multiplicity of infection } \\ \text { CPE } & \text { Cytopathic effect } \\ \text { TCID }_{50} & \text { Median tissue culture infectious dose } \\ \text { LD }_{50} & \text { Median lethal dose } \\ \text { D }_{10} & \text { Decimal reduction dose } \\ \text { HA } & \text { Hemagglutination assay } \\ \text { PBS } & \text { Phosphate-buffered saline } \\ \text { SDS-PAGE } & \text { Sodium dodecyl sulfate polyacrylamide gel } \\ & \text { electrophoresis } \\ \text { HEK-293 } & \text { Human embryonic kidney-293 } \\ \text { cDNA } & \text { Complementary DNA } \\ \text { PCR } & \text { Polymerase chain reaction } \\ \text { ELISA } & \text { Enzyme-linked immunosorbent assay } \\ \text { HRP } & \text { Horseradish peroxidase } \\ \text { OD } & \text { Optical density } \\ \text { BAL } & \text { Bronchoalveolar lavage } \\ \text { LPA } & \text { Lymphocyte proliferation assay } \\ \text { PHA } & \text { Phytohemagglutinin } \\ \text { Th1 } & \text { T helper 1 } \\ \text { CTL } & \text { Cytotoxic T lymphocyte } \\ \text { HA0 } & \text { Hemagglutinin precursor protein } \\ \text { NA } & \text { Neuraminidase } \\ & \end{array}$




$\begin{array}{ll}\text { WIV } & \text { Whole inactivated virus } \\ \text { M } & \text { Matrix protein }\end{array}$

\section{Introduction}

Recent studies have shown that, compared with chemical and UV treatments, the immunogenic epitopes of gamma-irradiated influenza A virus ( $\gamma$-Flu) remain largely unchanged during treatment, resulting in a more potent induction of antibody- and cell-mediated immune responses [1-3]. These findings suggest that the use of $\gamma$-rays, which preferentially target the viral genome and have little effect on the functional properties of viral proteins, preserves the vaccine's ability to prime cross-reactive effector and memory cytotoxic T-cells, making it a promising candidate technique for the development of influenza vaccine with potential protection against both seasonal and pandemic influenza infections [3-5].

In general, the immunogenicity of $\gamma$-irradiated viruses is mainly dependent on radiation conditions, particularly the gamma-irradiation dose and the temperature [6]. David et al. reported that exposure of influenza A virus [A/Puerto Rico/8/34 (H1N1) (A/PR8)] to high-dose gamma irradiation at room temperature can adversely affect the immunogenicity of the $\gamma$-Flu vaccine [6]. Therefore, a lack of precise optimization of radiation conditions, accompanied by the Bremsstrahlung process, the phenomenon in which secondary radiation produced during gamma irradiation can increase the likelihood of unwanted alterations to vaccine epitopes [6, 7]. Accordingly, the incorporation of effective adjuvants in a vaccine formulation may increase the potency of an inactivated influenza vaccine [8].

There is increasing evidence of the immunomodulatory effect of interferons (IFNs) and their ability to enhance immune responses to vaccines [9-12]. A novel class of IFN, the interferon-lambda (IFN- $\lambda$ ) family, or type III IFNs, with IFN- $\alpha / \beta$-like antiviral activity, has been discovered recently [9]. IFN- $\lambda$ is predominantly secreted by epithelial cells of the airway following infection with respiratory viruses (notably influenza virus), and helps to create antiviral conditions in the respiratory tract $[13,14]$. Among the subtypes of the IFN- $\lambda$, interleukin-28B (IL-28B) has the highest bioactivity, indicating its great potential for clinical applications $[15,16]$. In addition to its potent antiviral effects in herpes simplex virus type 2 (HSV-2) and poxvirus infection models $[17,18]$, studies have demonstrated the in vivo immunostimulatory properties of IL-28B as a novel adjuvant to improve the adaptive vaccine responses in models of human immunodeficiency virus (HIV) and HSV-2 infections. Collectively, the immune-modulating capacity of IL-28B makes this kind of cytokine a promising candidate for use in vaccines [17, $19,20]$. In this study, we investigated the immunogenicity of a gamma-irradiated $\mathrm{H} 1 \mathrm{~N} 1$ vaccine and the adjuvanticity of a plasmid encoding mouse IL-28B- when added to the inactivated vaccine in a $\mathrm{BALB} / \mathrm{c}$ mouse model.

\section{Materials and methods}

\section{Cells and viruses}

The mouse-adapted human influenza virus strain $\mathrm{A} / \mathrm{PR} / 8 / 34$ [A/Puerto Rico/8/34 (H1N1)], obtained from the Pasteur Institute (Tehran, Iran), was propagated in vitro by infecting Madin-Darby canine kidney (MDCK) cells at a multiplicity of infection (MOI) of 6 . After a cytopathic effect (CPE) was observed, the virus-containing culture supernatant was harvested and concentrated using the ultrafiltration system with a 100-kDa cutoff, and the virus was titrated in MDCK cell monolayers using a median tissue culture infectious dose $\left(\mathrm{TCID}_{50}\right)$ assay. Anesthetized mice were inoculated intranasally with $50 \mu \mathrm{l}$ of infectious virus, to determine the median lethal dose $\left(\mathrm{LD}_{50}\right)$ of A/PR8 for viral challenge. The virus concentration and $\mathrm{LD}_{50}$ titer were calculated by the Spearman-Karber method [21].

\section{Virus inactivation}

A ${ }^{60} \mathrm{Co} \gamma$-ray source (GammaCell 220; MDS Nordion, Ottawa, Canada) at a dose rate of $1.42 \mathrm{~Gy} / \mathrm{s}$ and activity of $6048 \mathrm{Ci}$ was used for radiation exposure. During treatment, concentrated virus stocks were kept frozen on dry ice and irradiated with gamma radiation at doses of $5,10,15,20$, 25,28 , and $30 \mathrm{kGy}$ (two repeats for each dose). After exposure, the survival of irradiated viruses was determined by TCID $_{50}$ assay, and a dose/survival curve was plotted using OriginPro 6.1 software, followed by the calculation of the decimal reduction dose $\left(\mathrm{D}_{10}\right)$ value and optimum dose of gamma rays. The residual viral infectivity was evaluated by inoculation of irradiated samples onto MDCK monolayers 4 times at $48 \mathrm{~h}$ intervals under similar conditions. A lack of visible $\mathrm{CPE}$, determined by visually monitoring sequential passages, indicated a complete loss of virus infectivity [22]. The evaluation of each virus suspension was repeated in duplicate.

\section{Hemagglutination assay (HA)}

To evaluate the structural integrity of the hemagglutinin after exposure to different doses of gamma irradiation, twofold serially diluted live and irradiated viruses in $1 \mathrm{x}$ phosphate-buffered saline (PBS) were prepared using a 96-well U-bottomed plate in a total volume of $50 \mu \mathrm{l}$ and incubated with an equal volume of $0.5 \%$ chicken erythrocyte 
suspension for 1 hour at room temperature [1,23]. All samples were analyzed in duplicate.

\section{Sodium dodecyl sulfate polyacrylamide gel electrophoresis (SDS-PAGE)}

The Laemmli SDS-PAGE system was used to assess the quality of viral proteins before and after radiation at the optimum dose [6]. Irradiated and non-irradiated specimens in sample buffer containing SDS and beta-mercaptoethanol were heated at $85{ }^{\circ} \mathrm{C}$ for 20 minutes and subjected to electrophoresis in a $5-12.5 \%$ Tris- $\mathrm{HCl}$ gel. The comprehensive protein profiling of viruses was visualized by Coomassie brilliant blue staining.

\section{Mouse IL-28B}

Lyophilized plasmid pUNO1 encoding mouse IL-28B (mIL28B) was purchased from InvivoGen (San Diego, USA) and prepared on a large scale using an EndoFree ${ }^{\circledR}$ Plasmid Purification Giga Kit (QIAGEN) in accordance with manufacturer's instructions for further in vivo experiments.

To evaluate the expression of the mIL-28B gene in mammalian cells, a monolayer culture of human embryonic kidney 293 (HEK-293) cells was transfected with the mIL-28B plasmid using Attractene Transfection Reagent (QIAGEN). Total RNA was then extracted and complementary DNA (cDNA) was synthesized using a High Pure RNA Isolation Kit (Roche) and a PrimeScriptTM RT Reagent Kit (TaKaRa), respectively, employing the protocols recommended by the manufacturers. Subsequently, the expression of the mIL-28B gene was confirmed by the amplification of mIL-28B cDNA using polymerase chain reaction (PCR) with gene-specific primers.

\section{Immunization of mice and viral challenge}

Sixty-five 6- to 8-week-old female BALB/c mice were randomly divided into five groups (13 mice in each group) and anesthetized intraperitoneally with ketamine-xylazine solution at a dose of $50 \mathrm{mg} / \mathrm{kg}$ and $20 \mathrm{mg} / \mathrm{kg}$, respectively. The mice were then inoculated intranasally three times at one-week intervals with $50 \mu \mathrm{l}$ of $\gamma$-Flu $\left(1.02 \times 10^{9} \mathrm{HAU}\right)$, either with or without mIL-28B adjuvant (50 $\mu \mathrm{g} /$ mouse). As control groups, anesthetized mice were treated with $50 \mu \mathrm{g}$ of one of the following reagents: mIL-28B plasmid, empty plasmid, or PBS (Fig. 1).

One week after the last immunization, mice were anesthetized and challenged intranasally with $10 \mathrm{LD}_{50}$ of an $\mathrm{A} /$ $\mathrm{PR} / 8 / 34$ (H1N1) influenza virus stock that had been propagated in MDCK cells, in $50 \mu \mathrm{l}$ PBS. Survival and morbidity were monitored daily for 14 days after challenge. Mice that lost more than $25 \%$ of their body weight were considered to have reached the experimental endpoint and were euthanized. In parallel experiments, lungs (three mice in each group) were harvested and homogenized on day 4 after challenge, followed by the determination of the virus titer using the Madin-Darby canine kidney (MDCK)/hemagglutination assay (HA). To release the virus, the homogenates were frozen and thawed three times, and their supernatants, either undiluted or diluted from 10- to $10^{6}$-fold (in tenfold steps), were added to triplicate wells of MDCK cells to a total volume of $30 \mu \mathrm{l}$. After incubation for $1 \mathrm{~h}, 170 \mu \mathrm{l}$ of infection medium containing $4 \mu \mathrm{g}$ of trypsin per ml was added to each well. After incubation for $48 \mathrm{~h}$ at $37^{\circ} \mathrm{C}$ in a humidified incubator containing $5 \% \mathrm{CO}_{2}$, the presence of virus was assessed by co-incubation of the culture supernatant with chicken red blood cells. Lung virus titers were determined by interpolation of the dilution endpoint that infected the cells in $50 \%$ of the wells and as $\log _{10} \mathrm{TCID}_{50}$ [24].

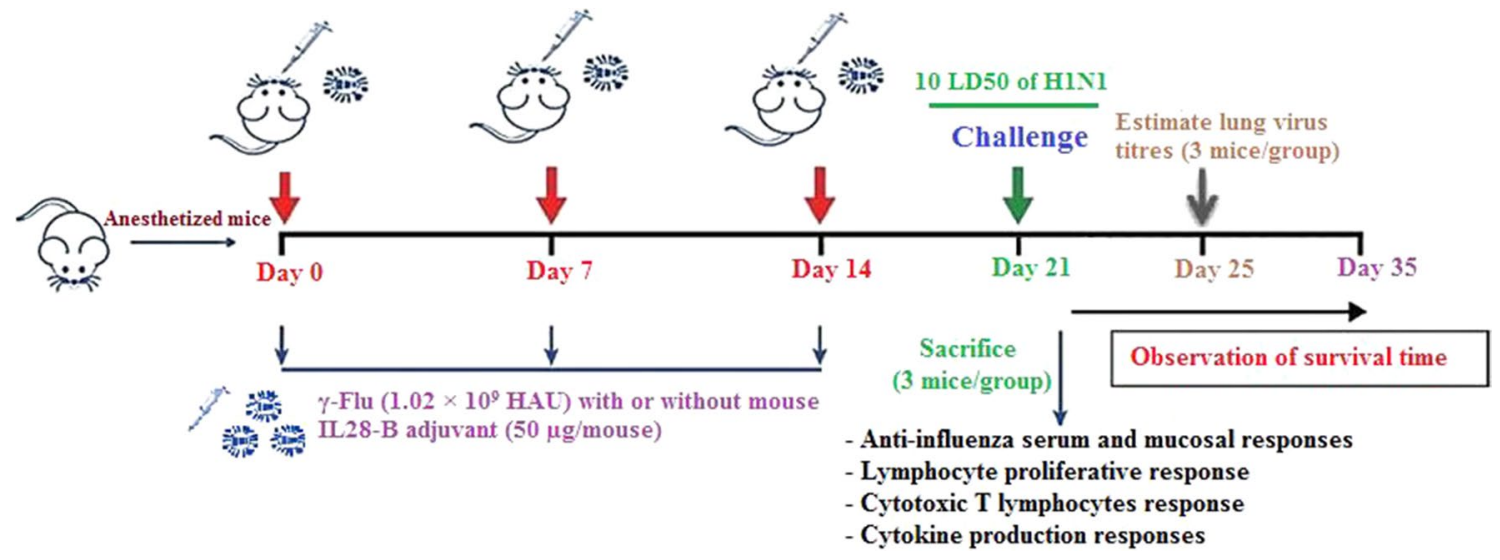

Fig. 1 The schedule for immunization of mice 


\section{Influenza-virus-specific IgG responses}

Blood samples were collected from three individual mice from each group by orbital sinus bleeding 7 days postvaccination, and serum levels of influenza-virus-specific total $\operatorname{IgG}, \operatorname{IgG} 1$, and $\operatorname{IgG} 2$ a were determined by enzymelinked immunosorbent assay (ELISA) as described previously [25]. Briefly, ELISA plates were coated with A/ PR8 vaccine at a concentration of $4 \mu \mathrm{g} / \mathrm{ml}$ and sequentially incubated with diluted serum samples and horseradish peroxidase (HRP)-conjugated goat anti-mouse $\operatorname{IgG}, \mathrm{IgG} 1$, or IgG2a (Sigma-Aldrich) for $2 \mathrm{~h}$ at room temperature, followed by the addition of HRP substrate to develop the colorimetric assay. After stopping the reaction with $2 \mathrm{M}$ $\mathrm{H}_{2} \mathrm{SO}_{4}$, the optical density (OD) in the ELISA plate wells was measured at $450 \mathrm{~nm}$. The endpoint ELISA titer was defined as the highest serum dilution generating a signal that was at least three times stronger than that obtained using samples from control mice at the same dilutions.

\section{Influenza-virus-specific secretory lgA response}

On day 21, nasal and bronchoalveolar lavage (BAL) fluids were collected from sacrificed mice (three mice in each group) by washing the nasal cavities and flushing the lungs 5 times with $1 \mathrm{ml}$ of PBS containing Roche's complete protease inhibitor cocktail. The samples were then centrifuged at $400 \times g$ for $10 \mathrm{~min}$ at $4{ }^{\circ} \mathrm{C}$, and the supernatants were collected. Antibodies in the recovered nasal and BAL fluids were detected by ELISA using HRP goat anti-mouse (IgA) secondary antibody as described above.

\section{Lymphocyte proliferation assay (LPA)}

One week after the final administration of the vaccine preparation, the spleens of three mice per group were removed aseptically and processed to make single-cell suspensions for in vitro analysis of cellular immune responses. In brief, splenocytes at a density of $2 \times 10^{5}$ cells/well were seeded in each well of a 96 MicroWell plate (Nunc, Denmark) and stimulated at $37{ }^{\circ} \mathrm{C}$ in a humidified atmosphere containing $5 \% \mathrm{CO}_{2}$ for $48 \mathrm{~h}$ with $\gamma$-A/PR8 $(4 \mu \mathrm{g} / \mathrm{ml})$ as the specific antigen for the vaccine groups, phytohemaggluti$\operatorname{nin}(\mathrm{PHA}, 5 \mu \mathrm{g} / \mathrm{ml}$ ) for the positive control, or without any stimulating antigen. All samples were run in triplicate for each mouse. At $48 \mathrm{~h}$ post-stimulation, lymphoproliferation was evaluated by adding $30 \mu \mathrm{l}$ of $5 \mathrm{mg} / \mathrm{ml}$ MTT solution to per well. After further incubation for $4 \mathrm{~h}, 100 \mu \mathrm{l}$ of dimethyl sulfoxide was added to each well to dissolve formazan crystals, and the color intensity was measured at $540 \mathrm{~nm}$.
The results were reported as a stimulation index using the following calculation:

Stimulation index $=(O D$ of stimulated cells $-O D$ of unstimulated cells)/OD of unstimulated cells [26].

\section{Analysis of cytokine secretion}

To assess cytokine profiles, one week after the third immunization, spleen cells were prepared and restimulated as described above. At $48-72 \mathrm{~h}$ post-stimulation, the culture supernatants were collected, and the ability of restimulated cells to secrete T helper 1 (Th1) (IFN- $\gamma$, IL-12) and Th2 (IL-4) cytokines was assessed using commercially available cytokine-specific sandwich-based ELISA kits (R\&D, USA) as per manufacturer's instructions.

\section{Granzyme B analysis}

To evaluate cytotoxic T lymphocyte (CTL) responses in immunized mice, on day 21 , mononuclear cells from the spleens of immunized mice $\left(2 \times 10^{5}\right.$ cells/well $)$ were plated in triplicate and incubated in the presence of $4 \mu \mathrm{g}$ of $\gamma-\mathrm{A} /$ PR8 or $5 \mu \mathrm{g}$ of PHA per $\mathrm{ml}$ or medium alone for $48 \mathrm{~h}$ at $37^{\circ} \mathrm{C}$. The supernatants were then collected and assayed for T-cell lytic activity using a commercially available granzyme B sandwich-based ELISA kit (R\&D, USA) according to the manufacturer's protocol.

\section{Quantification of IL-6 and IL-10 in lung homogenate samples by ELISA}

To investigate inflammatory responses, the lungs of three mice per group were harvested aseptically on day 21 and homogenized at $4{ }^{\circ} \mathrm{C}$ in 4 volumes of PBS containing complete protease inhibitor cocktail (Roche) using a tissue homogenizer. The samples were then centrifuged at 9000 $\times g$ for 10 min at $4{ }^{\circ} \mathrm{C}$ to harvest the lung supernatants for cytokine analysis. Concentrations of IL-6 and IL-10 were determined using commercially available sandwich-based ELISA kits (R\&D, USA) following the manufacturer's recommendations. All samples were assayed in triplicate for each mouse.

\section{Statistical analysis}

All values were expressed as the mean $\pm \mathrm{SD}$. The comparative analysis was done by one-way ANOVA test. A KaplanMeier curve was also used for the analysis of survival rates, and statistical significance was determined by chi-square test. A $p$-value $\leq 0.05$ was considered statistically significant. All statistical analysis was carried out using SPSS version 16 (SPSS Inc., Chicago, IL, USA). 


\section{Results}

\section{Inactivated virus preparation}

For the preparation of whole inactivated influenza virus, frozen concentrated A/PR8 stocks with an initial titer of $10^{5.75}$ / $\mathrm{ml}$ were subjected to increasing doses of gamma radiation (5-30 kGy) from a cobalt-60 irradiation facility, and the residual virus infectivity was assessed using a $\mathrm{TCID}_{50}$ assay. Using 50\% endpoint titers of irradiated and control samples (Table 1), a dose/survival curve (Fig. 2A) was generated using OriginPro 6.1 software and used to calculate the $\mathrm{D}_{10}$ value, which is the dosage of gamma radiation required to

Table 1 Virus titers and dose of gamma radiation

\begin{tabular}{ll}
\hline $\begin{array}{l}\text { Dose of gamma- } \\
\text { radiation (kGy) }\end{array}$ & $\begin{array}{l}\text { Virus titers } \\
\left(\mathrm{TCID}_{50} /\right. \\
\left.\mathrm{ml}^{\prime}\right)\end{array}$ \\
\hline 0 & $10^{5.75}$ \\
5 & $10^{3.75}$ \\
10 & $10^{2.5}$ \\
15 & $10^{2}$ \\
20 & $10^{1.5}$ \\
25 & $10^{1.5}$ \\
28 & $<$ LOQ \\
30 & $<$ LOQ \\
\hline The limit of & quantifica- \\
tion (LOQ) of our median tis- \\
sue culture infectious dose assay \\
was 1.5 TCID $50^{2} / \mathrm{ml}$
\end{tabular}

produce $1 \log _{10}$ reduction in the infectivity of the virus population [5]. Based on the log-linear regression equation ( $Y$ $=5.15-0.205 \mathrm{X})$ provided by the dose/survival curve, the $\mathrm{D}_{10}$ value was estimated to be $4.878 \mathrm{kGy}$. Based on the $\mathrm{D}_{10}$ value, the initial titer $\left(10^{5.75} / \mathrm{ml}\right)$, and $5.75 \log _{10}$ reductions in titer to achieve the complete loss of virus infectivity, the minimum dose required for the complete inactivation (the optimum inactivation dose) was calculated using the formula “ $\mathrm{D}_{10}$ value $\times 5.75$ " and found to be $28.0485 \mathrm{kGy}$. Complete inactivation of the virus was confirmed by the absence of viral replication and a lack of CPE formation following four serial passages in MDCK cells (safety test). Given that no virus infectivity was detected in monolayers infected with either 28 or $30 \mathrm{kGy} \gamma$-A/PR8, the irradiation dose of $28 \mathrm{kGy}$ could be considered sufficient for complete inactivation of the virus.

\section{The effect of $\gamma$-radiation on virus antigenicity}

Since the HA assay is based on the ability of influenza hemagglutinin to agglutinate erythrocytes, the reduction of HAU titers after radiation may be correlated with structural damage. Although the results of the HA assay did not reveal any change in the antigenic characteristic of the virus preparations upon radiation at doses ranging from 0 to $25 \mathrm{kGy}$, the hemagglutination activity was reduced "by half" compared to the control when the virus preparation received a dose of 28 or $30 \mathrm{kGy}$. Accordingly, $28 \mathrm{kGy}$ of radiation was chosen as the optimum dose of $\gamma$-rays for complete inactivation of the virus with the least effect on the functionality of the HA protein. We also used SDS-PAGE to evaluate the quality

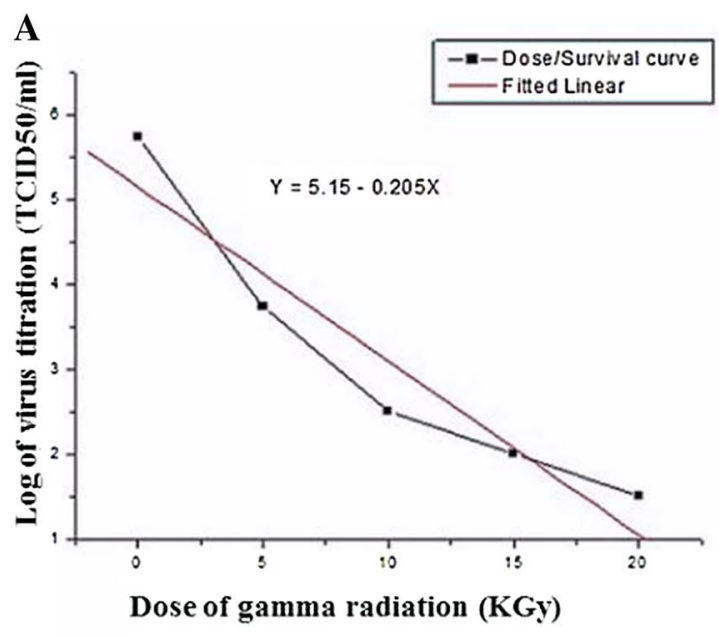

Fig. 2 The effect of gamma irradiation on the infectivity and structure of influenza A virus. (A) Dose/response curve. A/PR8 samples were exposed to increasing doses of gamma rays on dry ice, and the decrease in infectivity was assessed by $\mathrm{TCID}_{50}$ assay. (B) Investiga-

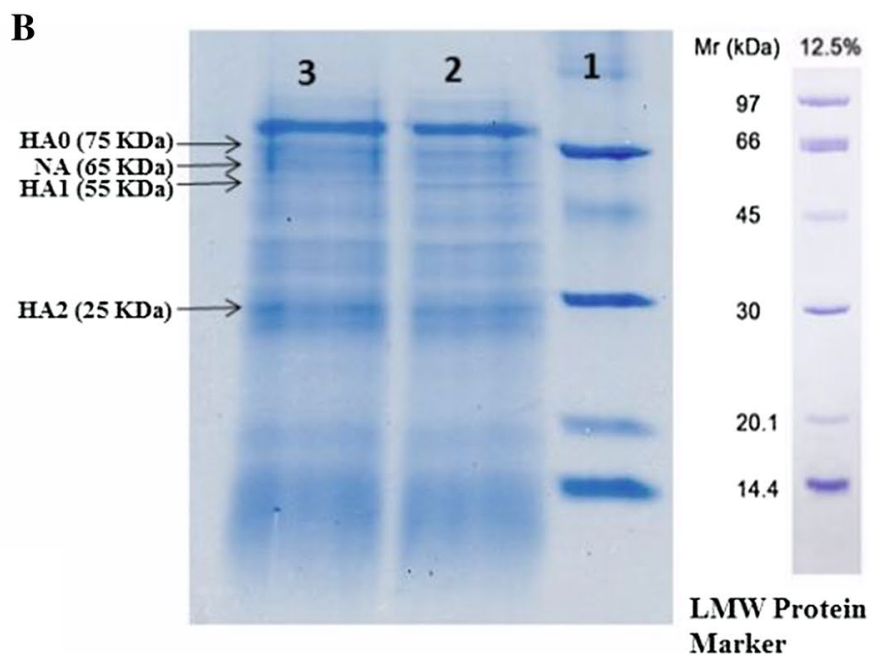

tion of the quality of viral proteins by SDS-PAGE. Lane 1, protein marker; lane 2, control virus; lane 3, $\gamma$-ray-inactivated A/PR8 using a radiation dose of $28 \mathrm{kGy}$. Molecular weights are according to those reported by David et al. [6]. 
of viral proteins in A/PR8 viruses exposed to $28 \mathrm{kGy}$ of gamma rays. As shown in Fig. 2B, the crucial viral proteins involved in viral attachment and penetration, including the hemagglutinin precursor protein (HA0) and its cleaved forms (HA1, HA2), as well as neuraminidase (NA) were detectable in control and irradiated samples. Consequently, $\gamma$-ray-inactivated A/PR8 viruses using a radiation dose of 28 kGy were applied for vaccine preparation.

\section{Systemic antibody responses}

To evaluate the effect of $\gamma$-Flu adjuvanted with the IL-28B plasmid on humoral immunity, mice were immunized intranasally with $\gamma$-Flu or $\gamma$-Flu and IL-28B plasmid on days 0 , 7 , and 14 . One week after the last immunization, sera were collected and tested by endpoint Ab enzyme-linked immunosorbent assay. The results showed that vaccination of mice with either $\gamma$-Flu alone or together with IL-28B adjuvant elicits a high level of specific total IgG compared to the control groups (IL-28B plasmid, PBS, and control plasmid) $(p<0.001)$. However, the total IgG titer in mice primed with the adjuvanted $\gamma$-Flu vaccine was significantly higher than those treated with $\gamma$-Flu alone $(p<0.001)$ (Fig. 3A).

To assess the induced adaptive immune responses, the sera were also subjected to IgG isotype analysis. In the comparison between the vaccinated and the control groups, a statistically significant difference $(p<0.001)$ in the level of the IgG isotype was observed (Fig. 3B and C). A similar pattern was also observed for IgG isotype antibody titers in mice receiving adjuvanted $\gamma$-Flu vaccine in comparison to those given non-adjuvanted vaccine ( $\gamma$-Flu alone) $(p<$ 0.001). As shown in Fig. 3D, the level of IgG2a (a marker for Th1-type immunity) was higher than that of IgG1 (a marker for Th2-type immunity) in response to vaccination with $\gamma$-Flu adjuvanted with the IL-28B plasmid, demonstrating that the co-administration of $\gamma$-Flu and IL-28B plasmid induced an enhanced balanced Th1/Th2 immune response with more bias toward the Th1 phenotype. No considerable differences were observed in the levels of influenza-virusspecific IgG among the control groups.

\section{Mucosal immune responses}

The ability of IL-28B to boost the mucosal antibody response of the $\gamma$-inactivated influenza vaccine was evaluated by testing nasal washes and bronchoalveolar lavage fluid (BALF) of immunized mice using the ELISA method one week after the last immunization. Analysis of antibodies in BALF (Fig. 4) illustrated that IL-28B significantly enhanced the BALF IgA response to the $\gamma$-Flu vaccine $(p$
Fig. 3 Levels of anti-influenzavirus antibodies in mouse sera one week after the last immunization. (A) Total IgG titers. (B) IgG1 titers. (C) IgG2a titers. (D) $\mathrm{IgG} 2 \mathrm{a} / \mathrm{IgG} 1$ ratio. Values for individual sera are expressed at $450 \mathrm{~nm}$ in each group $(\mathrm{n}=$ $3)$. Differences between mice immunized with $\gamma$-Flu+IL-28B plasmid and $\gamma$-Flu alone were statistically highly significant according to one-way ANOVA results $(* * *, p<0.001)$. The graphs also illustrate that the levels of influenza-virus-specific antibodies in all vaccinated and control groups differed considerably $(p<0.001)$.
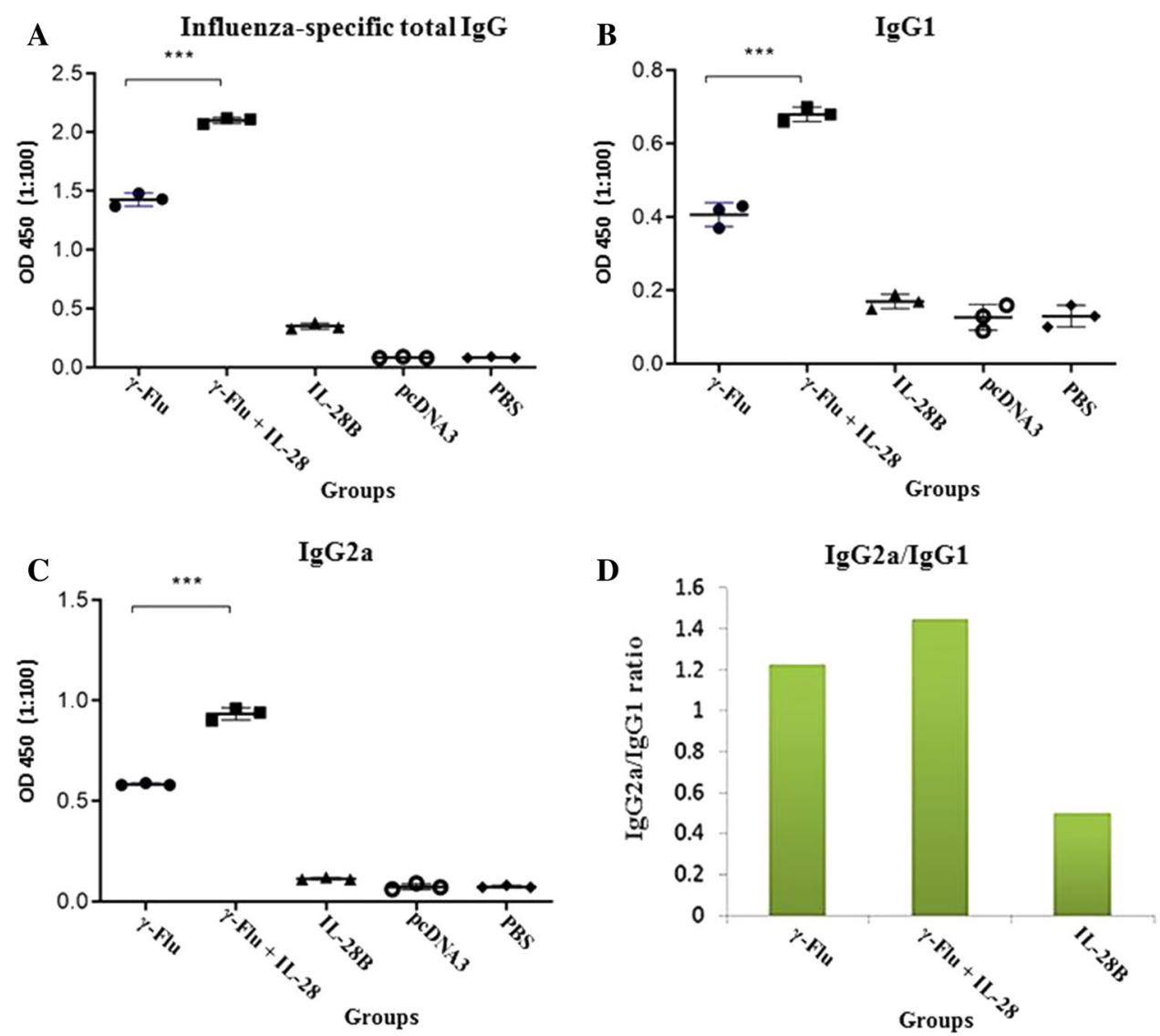
Fig. 4 Influenza-virus-specific sIgA concentrations in mucosal secretions of each treated group. BAL fluids and nasal washes were collected from three mice per group and analyzed by ELISA for the presence of SIgA. Differences among individual groups were analyzed by oneway ANOVA and shown as *** for $P<0.001$ and $* *$ for $P<$ 0.01 . A statistically significant difference between all experimental and control groups was also observed $(P<0.001)$.

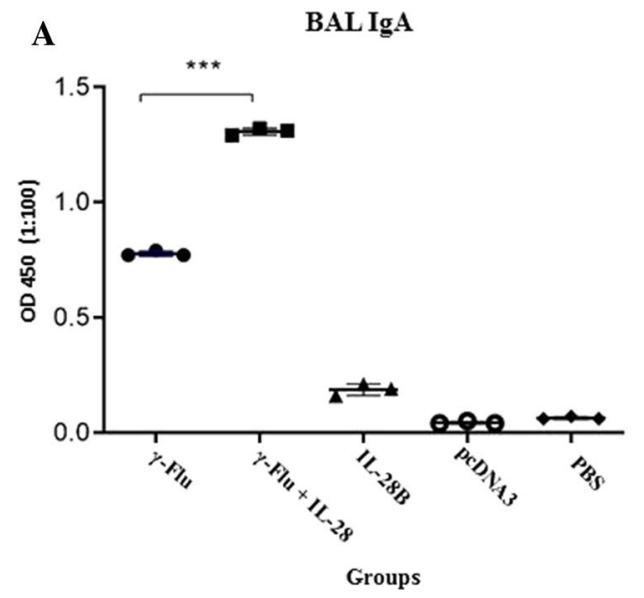

$<0.001)$. Similar results were obtained using nasal washes $(p<0.01)$, suggesting the potential of IL-28B as an adjuvant to induce improved vaccine-specific mucosal antibody responses. Furthermore, the vaccine-induced nasal and BAL IgA responses were much higher than those observed in the negative control groups $(p<0.001)$. However, no significant differences in secretory IgA titer in nasal and BAL fluids were found among three control groups.

\section{Lymphocyte proliferation assay}

The adjuvant properties of IL-28B were further analyzed by LPA assay using restimulation of cultured spleen cells with $\gamma$-inactivated influenza virus as the specific antigen on day 21. As shown in Fig. 5, the vaccine formulation containing the IL-28B plasmid as adjuvant significantly increased the magnitude of cell proliferation compared to the non-adjuvanted group $(p<0.01)$, indicating that the adjuvanticity of IL-28B promotes vaccine-induced cell-mediated immunity. Also, the lymphoproliferative activity of splenocytes from vaccinated mice was considerably higher than that elicited in spleen cells from the control groups $(p<0.001)$. As expected, mice in the groups treated with IL-28B plasmid, control plasmid, or PBS showed very little lymphoproliferative response.

\section{Cytokine profile in response to in vitro antigen restimulation}

To further investigate the effect of IL-28B on the polarization of the immune response, cytokine secretion profiles in splenocyte culture supernatants of immunized mice were analyzed by ELISA one week after the final immunization. Notably, Th1 cell differentiation is mainly induced by IFN- $\gamma$ and IL-12, while Th2 bias is associated with cytokines such as IL-4. As shown in Fig. 6A-C, the level of IFN- $\gamma$ secretion in mice vaccinated with adjuvanted $\gamma$-Flu was much higher than in mice given only $\gamma$-Flu $(p$

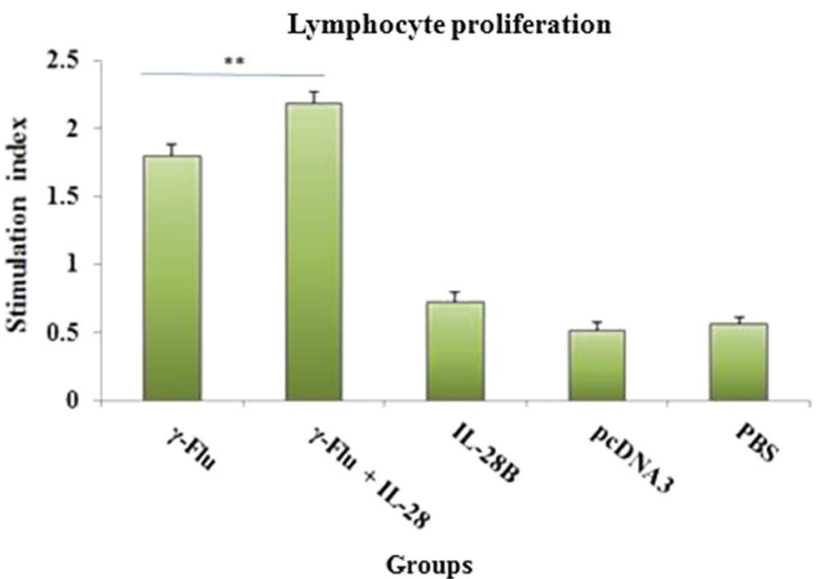

Fig. 5 Assessment of lymphoproliferative responses after in vitro restimulation of cultured spleen cells with $\gamma$-Flu $(4 \mu \mathrm{g} / \mathrm{ml})$. Three mice in each group were sacrificed 7 days after the third immunization, and splenocytes proliferation in response to antigen stimulation was estimated using an MTT assay. **indicates a statistically significant difference between mice that received $\gamma$-Flu + IL-28B plasmid and $\gamma$-Flu alone, as determined by one-way ANOVA $(P<0.01)$. Values are presented as the mean \pm SD for three samples. Differences between all immunized and control groups were statistically highly significant $(p<0.001)$.

$<0.001)$. A similar trend was also observed for IL-12 and IL-4 in splenocyte culture supernatants $(p<0.001)$. Furthermore, splenocytes from mice immunized with $\gamma$-Flu alone or $\gamma$-Flu adjuvanted with the IL-28B plasmid exhibited a high-level of IFN- $\gamma$, IL-12, and IL-4 secretion in comparison with the control groups $(p<0.001)$. The results also illustrated that adjuvanted $\gamma$-Flu vaccine induced higher levels of IFN- $\gamma$ and IL-12 expression than of IL-4 expression, indicating that adjuvantation with IL28B could elicit a potent Th1 and Th2 balanced response with a Th1 bias to $\gamma$-inactivated influenza vaccine. There was no difference in the expression level of Th1 and Th2 cytokines in the control groups, which is consistent with results of previous studies showing that mice in the control 

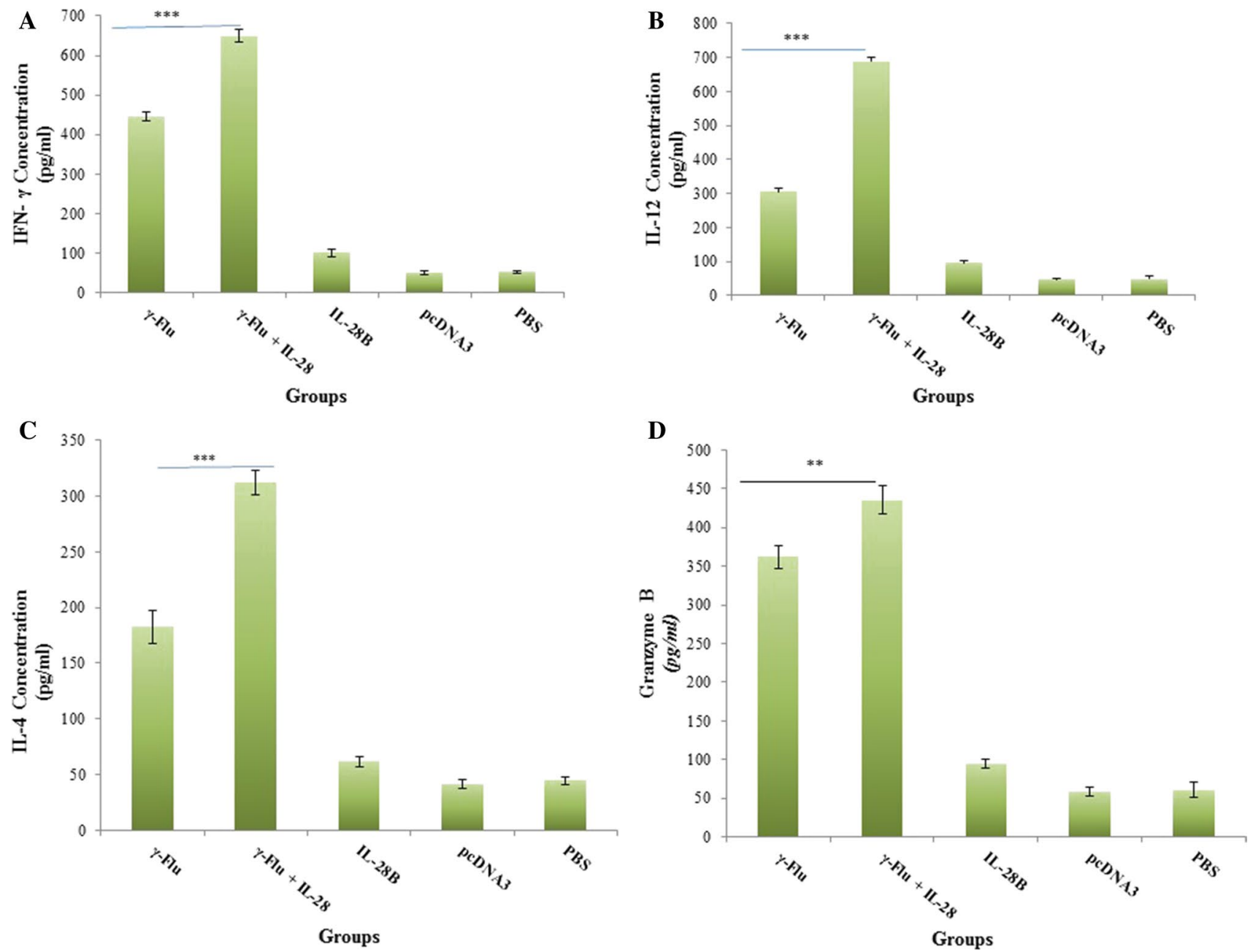

Fig. 6 Comparison of cytokine profiles and granzyme B production in splenocyte culture supernatants restimulated with $\gamma$-Flu. Results are representative of three independent experiments and are expressed as the mean \pm SD. One-way ANOVA was used to analyze differences

among groups. ***, $P<0.001$; **, $p<0.01$. The graphs also show a statistically significant difference between all vaccinated and control groups $(P<0.001)$.

groups did not exhibit any significant antigen-specific cytokine secretion $[19,25]$.

\section{Granzyme B production}

Granzyme B is a vital mediator of cytolysis that is involved in killing of influenza-virus-infected cells by $\mathrm{CD} 8^{+} \mathrm{T}$ cell. To evaluate whether the IL-28B adjuvant was able to improve the lytic activity of the $\gamma$-inactivated influenza vaccine, the recovered supernatants of splenocytes were tested by ELISA to determine the granzyme B concentration. As shown in Fig. 6D, a significantly higher granzyme B expression level was observed in mice given $\gamma$-Flu adjuvanted with the IL-28B plasmid than in those receiving $\gamma$-Flu alone $(p<0.01)$, suggesting that the number of activated influenza-virus-specific-cytotoxic T lymphocytes was higher when the IL-28B plasmid was incorporated in the vaccine

formulation. Also, the vaccine-induced CTL responses were much higher than those in the negative control groups $(p<$ 0.001). No significant difference was observed in the granzyme B levels among the control groups.

\section{IL-6 and IL-10 secretion in lungs}

The ability of IL-28B to modulate the inflammatory responses to the $\gamma$-inactivated influenza vaccine was assessed in lung homogenates of immunized mice using the ELISA method on day 21. Analysis of cytokine responses in lung homogenates revealed that intranasal immunization with adjuvanted $\gamma$-Flu vaccine significantly reduced the level of IL-6 secretion $(p<0.05)$ compared to immunization with $\gamma$-Flu alone (Fig. 7A). A similar trend was also observed for IL-10 in lung homogenates ( $p<0.01$ ), with less IL-10 secretion observed in mice immunized with $\gamma$-Flu adjuvanted 


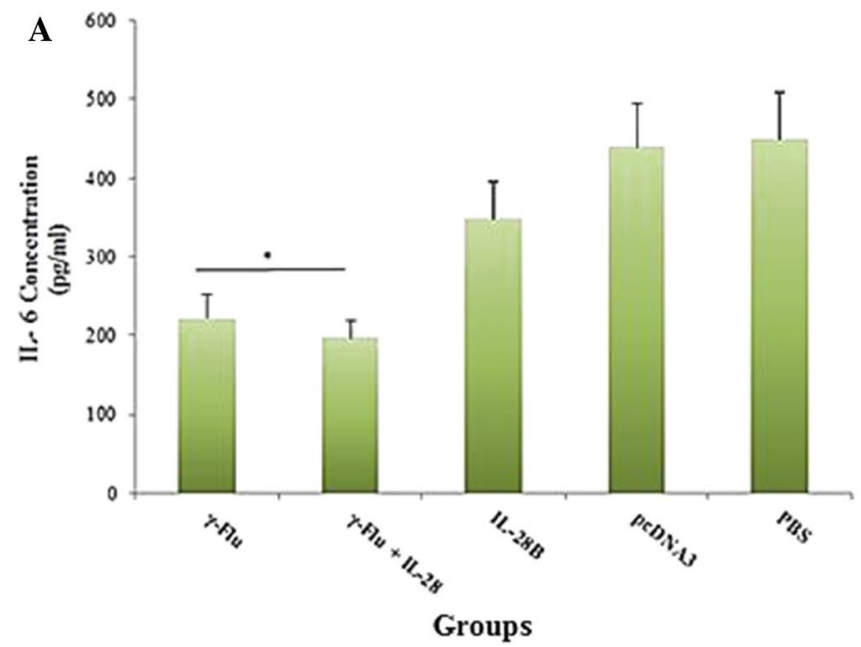

Fig. 7 Levels of inflammatory mediators in lung homogenate samples. Supernatants from homogenized lungs were harvested and examined for the presence of IL-6 and IL-10 using the ELISA method. In comparison to other groups, significance is indicated by $*$ for $p<0.05$ and $* *$ for $p<0.01$, as calculated by one-way ANOVA.

with the IL-28B plasmid than when treated with the nonadjuvanted vaccine (Fig. 7B). Furthermore, the vaccineinduced inflammatory responses were much weaker than those observed in the negative control groups $(p<0.001)$. There was no significant difference in IL-10 levels among the three control groups, whereas the level of IL-6 in mice receiving the IL-28B differed significantly from those in the other control groups $(p<0.001)$. Our data suggest that IL$28 \mathrm{~B}$ could be effective as an adjuvant for modulating the inflammatory response to the $\gamma$-inactivated influenza vaccine, particularly in reducing the number of IL-6-producing cells in the lung.

\section{Survival rate and effect of vaccination on lung viral loads}

As IL-28B significantly enhanced the cellular and mucosal immune response to $\gamma$-inactivated influenza vaccine, we next investigated whether the IL-28B adjuvant affects the protective effect of the vaccine (morbidity and survival rate) in a murine model. For this purpose, mice were challenged intranasally with a high lethal dose $\left(10 \mathrm{LD}_{50}\right)$ of $\mathrm{A} /$ $\mathrm{PR} / 8 / 34$ (H1N1) influenza virus on day 21 after the primary immunization and monitored for 2 weeks for body weight loss and survival. As expected, all of the mice in negative control groups showed rapid loss of body weight and died between days 12 and 14 post-challenge (Fig. 8A and B). The survival curve (Fig. 8B) showed significant protection (more than $80 \%$ survival) after challenge when mice were given $\gamma$-Flu adjuvanted with the IL28-B plasmid. In contrast, immunization with the $\gamma$-Flu vaccine alone provided

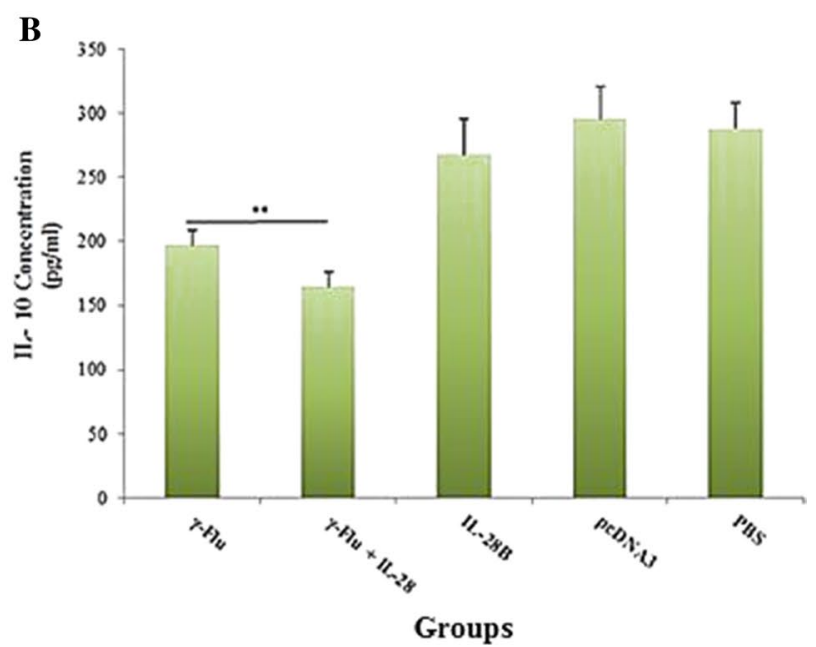

Among the three control groups (IL-28B plasmid, control plasmid, and PBS), a statistically significant difference $(p<0.001)$ in IL-6 levels for the IL-28B group was detected. However, no significant difference in IL-10 levels was seen between the control groups. Data are expressed as the mean $\pm \operatorname{SD}(n=3)$.

$50 \%$ protection. The mice receiving $\gamma$-Flu vaccine without adjuvant showed only mild morbidity, characterized by loss of body weight, and they recovered rapidly after challenge. However, morbidity rates in mice co-immunized with the $\gamma$-Flu vaccine and the IL-28B adjuvant were significantly lower than in those immunized with the vaccine alone $(p<$ 0.001 ) (Fig. 8A). We also carried out further experiments in order to estimate the virus titers in the lungs, using MDCK cells followed by a standard hemagglutination assay on day 4 after challenge with homotypic influenza viruses. As shown in Fig. 8C, virus titers in the lung were lower in mice receiving $\gamma$-Flu alone than in the controls, but the inhibition was more robust when the $\gamma$-Flu vaccine and the IL-28B adjuvant were administered simultaneously $(p<0.01)$. Furthermore, lung homogenates of mice immunized with either $\gamma$-Flu alone or adjuvanted with the IL-28B plasmid exhibited significantly lower lung viral loads than the control groups $(p<0.001)$. Together, our data demonstrate that a higher level of protective immunity in response to viral challenge is achieved when the $\gamma$-inactivated influenza vaccine is formulated with the IL-28B plasmid as an adjuvant.

\section{Discussion}

The use of whole inactivated virus (WIV) vaccines that are significantly more immunogenic than current subunit or split virion vaccines appears to be an ideal strategy for providing effective coverage against heterologous strains [27, 28]. Given the importance of preserving protective epitopes for vaccine efficacy, the inactivation methods used to prepare 

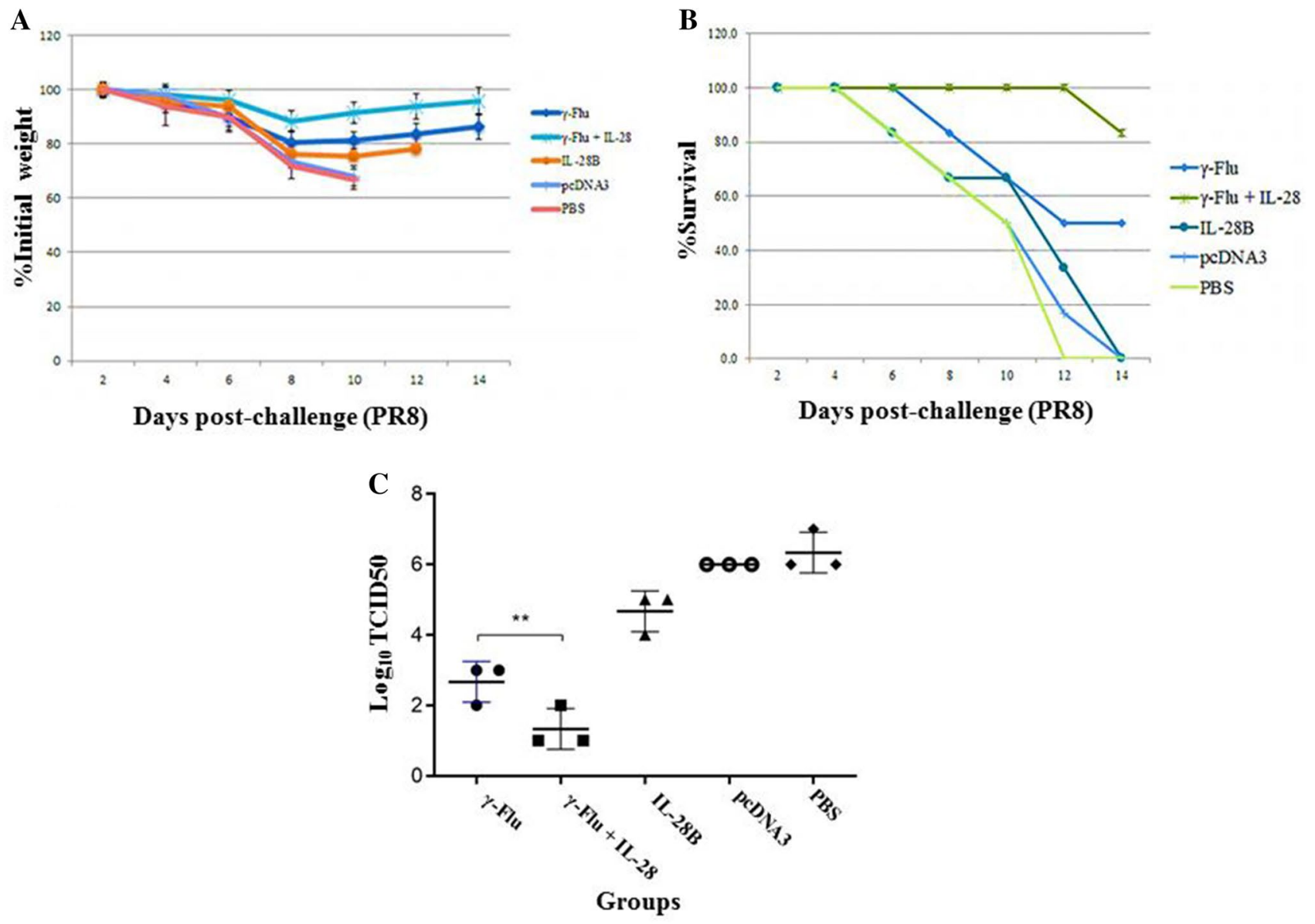

Fig. 8 Survival, weight loss, and lung virus titers in the experimental and control groups. Mice were immunized intranasally three times at one-week intervals with different vaccine preparations and challenged 7 days after the third immunization. Infected mice were followed up 14 days for survival and morbidity. Mice with a loss of total body weight $\geq 25 \%$ were euthanized. (A) Weight data expressed as the mean \pm SD $(n=7)$. One-way ANOVA was used for the assessment of statistical significance. (B) Survival data presented as the

WIV vaccines plays a critical role in the vaccine's ability to induce a potent immune response [1]. Several studies have shown that the immunogenicity of influenza virus particles inactivated using gamma radiation is significantly higher than that of virus particles inactivated by chemical (e.g., formaldehyde) or physical (UV radiation) treatments [1, $2,8,29]$. One advantage of gamma radiation over chemical agents and UV radiation is its high penetration power and the ability to be used with frozen preparations, thereby reducing free radical damage caused by radiolysis of water $[1,6]$.

To maintain the integrity of viral proteins, gamma irradiation should be limited to the minimum dose required for complete inactivation of the virus [30]. In this regard, we showed that there is a mathematical log-linear relationship $(\mathrm{Y}=5.15-0.205 \mathrm{X})$ between increasing radiation doses and percentage of animals surviving out of the total number monitored. Statistical significance determined by the Kaplan-Meier test. (C) On day 4 post-challenge, three mice in each group were sacrificed, and lung viral loads were determined by MDCK/ HA assay. ** Indicates a statistically significant difference between the $\gamma$-Flu group and the $\gamma$-Flu + IL-28B group $(p<0.01)$, as calculated by one-way ANOVA. The graph also shows a statistically significant difference between all vaccinated and control groups $(P<0.001)$.

decreasing virus titers. This was used to calculate the $\mathrm{D}_{10}$ value of $4.878 \mathrm{kGy}$ and the minimum inactivation dose of $28.0485 \mathrm{kGy}$. Based on a lack of detectable CPE for four passages as well and maintenance of most of the viral protein integrity, confirmed by HA assay and SDS-PAGE, 28 $\mathrm{kGy} \gamma$-A/PR8 was used for the WIV vaccine preparation. Intranasal immunization of BALB/c mice with $\gamma$-inactivated influenza vaccine three times at one-week intervals induced both cell- and antibody-mediated immunity by upregulating Th-1 (IFN- $\gamma$, IL-12) and Th-2 (IL-4) cytokines, with a bias toward Th1 cytokines, along with an increase in the total $\operatorname{IgG}$ titer and $\mathrm{IgG} 2 \mathrm{a} / \mathrm{IgG} 1$ ratio, suggesting that the $\gamma$-Flu vaccine formulation promoted a balanced Th1 and Th2 immune response with a tendency toward Th1. $\gamma$-Flu also increased the proliferation of $\mathrm{CD}^{+}{ }^{+} \mathrm{T}$ cells and influenza-virus-specific cytotoxic T-cells, and decreased the viral load in the 
lung after infection, which were associated with protection against a high lethal dose challenge with A/PR/8/34 (H1N1) influenza virus. Our findings demonstrate the ability of $\gamma$-Flu vaccines to induce an antiviral immune response, which is consistent with previous studies that showed the potential applicability of gamma-inactivated influenza whole-virion vaccines to elicit improved humoral immunity and a high level of cell-mediated immunity, as well as to confer effective protection against homologous and heterologous viral challenge $[1-3,6]$.

The efficacy of $\gamma$-vaccines can nonetheless be adversely affected by protein damage during irradiation due to the Bremsstrahlung process and/or radiation conditions $[6$, 7], and the usage of adjuvant strategies may be required to improve the immunogenicity of the vaccine. A recent study by Astill and colleagues showed that a $\gamma$-ray-inactivatedH9N2 vaccine adjuvanted with CPG ODN 2007 induced more potent humoral responses in chickens than the candidate vaccine alone [8]. Furthermore, the whole inactivated influenza viruses that were used in early vaccination campaigns induced inflammatory responses that caused significant pain and reactivity at the injection site. For this reason, split vaccines were developed that were safer. A major benefit of using adjuvants with WIV vaccines is that lower doses can be used to avoid reactogenicity [31].

IFN- $\lambda 3$ (IL-28B) belongs to the recently discovered IFN- $\lambda$ family and plays an important role in the adaptive immune response to viral infections. Morrow et al. demonstrated that co-administration of IL-28B as a genetic adjuvant could enhance both cellular and humoral immune responses induced by an HIV DNA vaccine [20]. Similarly, another study conducted by Zhou et al. revealed that both humoral and cellular immune responses elicited against an HSV2 DNA vaccine increased when the IL-28B plasmid was used as a vaccine adjuvant in the same vaccine formulation. They suggested that IL-28B has a stimulating effect on the adaptive immune responses, which makes it an appropriate candidate for further vaccine-related studies [19]. Regarding the expression pattern of the IFN- $\lambda$ receptor complex on a limited subset of cells (notably epithelial cells) and its probable role in creating antiviral conditions specifically in tissues with a high epithelial content (e.g., lung) [32], we investigated the immunoadjuvant potential of IL-28B to boost the vaccine-induced immune response when administrated intranasally with the $\gamma$-inactivated influenza vaccine. Our results demonstrate that co-immunization with the $\gamma$-inactivated influenza vaccine and the IL-28B plasmid elicits an enhanced balanced Th1/Th2 immune response with more bias towards Th1, as illustrated by a higher ratio of $\mathrm{IgG} 2 \mathrm{a} / \mathrm{IgG} 1$ and a bias toward Th1 cytokines, compared with $\gamma$-inactivated vaccine alone, which is in agreement with the ability of IL-28B to enhance antigen-specific adaptive immunity against a multiclade HIV Gag antigen in a
Th1- and IgG2a-biased fashion [20]. The levels of granzyme $\mathrm{B}$ and $\mathrm{CD}^{+}{ }^{+}$proliferation after treatment with $\gamma$-Flu vaccine adjuvanted with the IL-28B plasmid were considerably higher than those of the $\gamma$-Flu group, and the titer of virus in the lung was decreased more significantly if mice were given the $\gamma$-Flu vaccine with the IL-28B adjuvant, which was correlated with better protection against a lethal influenza virus challenge $\left(10 \mathrm{LD}_{50}\right)$.

Given the key role of SIgA in mucosal immunity and neutralization of influenza particles in the upper respiratory tract by blocking the attachment of the virus to mucosal surfaces $[33,34]$, and also the need for the presence of antigen-specific neutralizing antibodies in the lower respiratory tract to provide complete protection against pathogens that were not inhibited in the upper respiratory tract [35], the ability of $\gamma$-inactivated influenza vaccine to induce $\operatorname{sIgA}$ responses in the upper (nasal washes) and the lower (BAL fluids) respiratory tract was investigated. The results revealed that the administration of $\gamma$-Flu vaccine could significantly increase influenza-virus-specific sIgA titers in both nasal and BAL fluids compared to the control groups, indicating the potential of the vaccine candidate for inducing mucosal immunity as the first line of defense and for controlling the spread of influenza virus infection. Furthermore, an increased $\operatorname{sig} \mathrm{A}$ response in the respiratory tract after adjuvanted vaccine treatment in comparison with the $\gamma$-Flu group provides further support for the application of IL-28B as an adjuvant. Of note, higher levels of vaccine-induced IgA responses were observed in BAL fluid than in nasal washes, which is consistent with results obtained by intranasal immunization of $\mathrm{BALB} / \mathrm{c}$ mice with influenza virus-like particles containing matrix (M2) proteins, suggesting a significant correlation of antigen-specific IgA levels in bronchoalveolar lavage fluid and protection against influenza infections [36].

The cytokine IL-6 is a major mediator of inflammation that is involved in the modulation of cell-mediated immunity and the inflammatory reaction in response to influenza virus infection [37]. Several studies have demonstrated that overproduction of IL- 6 is closely related to the acute influenza inflammatory state, which results in progression to severe disease [38-41]. Reeth et al. showed that lower-respiratorytract disease in influenza-virus-infected-pigs is strongly associated with a reduction in the level of pro-inflammatory cytokines such as IL-6 in the lung [42]. Another study conducted by Quan et al. confirmed that immunization of mice with virus-like particles containing influenza virus $\mathrm{A} /$ PR8/34 (H1N1) hemagglutinin and matrix (M1) proteins significantly reduced the number of IL-6-secreting cells compared to the unimmunized (naïve) mice upon virus infection, indicating that excessively high levels of IL-6 in naïve mice might play an important role in increased inflammatory damage of the lung [43]. In the current study, we detected significantly reduced IL-6 expression in mice that 
were given either $\gamma$-Flu alone or $\gamma$-Flu adjuvanted with the IL-28B plasmid, and a decreased IL-6 response was also seen in the IL-28B group, indicating that IL-28B has strong potential to modulate inflammatory responses in the lung.

IL-10 is one of the major anti-inflammatory cytokines involved in negative regulation of both innate and adaptive immunity, which limits tissue damage by suppressing the immune response. However, the precise role of IL-10 in response to viral infections remains unclear. In this regard, seemingly contradictory results (both exacerbating and protective effects) have been reported regarding the effects of IL-10 on influenza virus infections [44, 45]. Sun et al. showed that the survival rate in IL-10 knockout mice after influenza infection was significantly higher than in wildtype mice, indicating an adverse effect of IL-10 on protective immunity against influenza infections. They found that IL-10 can interfere with the initial $\mathrm{CD}^{+}{ }^{+} \mathrm{T}$ cell function that is needed for an effective humoral immune response [44]. McKinstry et al. also demonstrated that enhanced survival rates and viral clearance in IL- $10^{-/-}$mice following a lethal challenge with a high dose of influenza virus was associated with increased $\mathrm{Th}-17$ polarized naïve $\mathrm{CD} 4^{+} \mathrm{T}$ cells, indicating that IL-10 had a suppressive effect on the development of IL-17 responses upon influenza virus infection and was responsible for an increased mortality rate in challenged wild-type mice [46]. In agreement with these observations, we confirmed that the $\gamma$-Flu-vaccine-induced IL-10 responses were much weaker than those induced in the negative control groups. As expected, IL-28B also significantly reduced the IL-10 response to the $\gamma$-Flu vaccine in lung homogenates, implying that IL-28B is a potent adjuvant that improves the protective efficacy of the vaccine.

\section{Conclusions}

The results of this study show that intranasal vaccination with $\gamma$-Flu can efficiently promote both mucosal and systemic humoral and cellular immune responses and confer protection against intranasal challenge with $10 \mathrm{LD}_{50}$ of H1N1 influenza virus. Intranasal immunization has also been shown to reduce the levels of IL- 6 and IL-10 in lung homogenates. Furthermore, IL-28B has strong potential as an adjuvant, as indicated by significantly enhanced specific adaptive immune responses and decreased levels of inflammatory cytokines, as well as improved protective responses at a high viral challenge dose.

Acknowledgements The authors would like to acknowledge the Pasteur Institute of Iran for financial support.

Funding This study was supported by the Pasteur Institute of Iran (grant 1029). This project was extracted from a PhD thesis.

\section{Compliance with ethical standards}

Conflict of interest The authors declare that they have no conflict of interest.

Ethical approval All experiments were performed according to the Ethics Committee for the Use and Care of Laboratory Animals of Islamic Azad University, Tehran Medical Branch, Iran (ethics number: IR.IAU. TMU.REC.1397.309).

\section{References}

1. Furuya Y, Regner M, Lobigs M, Koskinen A, Müllbacher A, Alsharifi M (2010) Effect of inactivation method on the cross-protective immunity induced by whole 'killed'influenza A viruses and commercial vaccine preparations. J Gen Virol 91(6):1450-1460

2. Müllbacher A, Ada G, Tha Hla R (1998) Gamma-irradiated influenza A virus can prime for a cross-reactive and cross-protective immune response against influenza A viruses. Immunol Cell Biol 66(2):153-157

3. Alsharifi M, Furuya Y, Bowden TR, Lobigs M, Koskinen A, Regner M, Trinidad L, Boyle DB, Müllbacher A (2009) Intranasal flu vaccine protective against seasonal and $\mathrm{H} 5 \mathrm{~N} 1$ avian influenza infections. PLoS ONE 4(4):e5336

4. Furuya Y, Chan J, Wan EC, Koskinen A, Diener KR, Hayball JD, Regner M, Müllbacher A, Alsharifi M (2011) Gamma-irradiated influenza virus uniquely induces IFN-I mediated lymphocyte activation independent of the TLR7/MyD88 pathway. PLoS ONE 6(10):e25765

5. Alsharifi M, Müllbacher A (2010) The [gamma]-irradiated influenza vaccine and the prospect of producing safe vaccines in general. Immunol Cell Biol 88(2):103

6. David SC, Lau J, Singleton EV, Babb R, Davies J, Hirst TR, McColl SR, Paton JC, Alsharifi M (2017) The effect of gammairradiation conditions on the immunogenicity of whole-inactivated influenza A virus vaccine. Vaccine 35(7):1071-1079

7. Fertey J, Bayer L, Grunwald T, Pohl A, Beckmann J, Gotzmann G, Casado JP, Schönfelder J, Rögner FH, Wetzel C, Thoma M (2016) Pathogens inactivated by low-energy-electron irradiation maintain antigenic properties and induce protective immune responses. Viruses 8(11):e319

8. Astill J, Alkie T, Yitbarek A, Taha-Abdelaziz K, Bavananthasivam J, Nagy É, Petrik JJ, Sharif S (2018) Examination of the effects of virus inactivation methods on the induction of antibody-and cell-mediated immune responses against whole inactivated $\mathrm{H} 9 \mathrm{~N} 2$ avian influenza virus vaccines in chickens. Vaccine 36(27):3908-3916

9. Egli A, Santer DM, O'Shea D, Barakat K, Syedbasha M, Vollmer M, Baluch A, Bhat R, Groenendyk J, Joyce MA, Lisboa LF (2014) IL-28B is a key regulator of $\mathrm{B}$ - and T-cell vaccine responses against influenza. PLoS Pathog 10(12):e1004556

10. Cardenas-Garcia S, Dunwoody RP, Marcano V, Diel DG, Williams RJ, Gogal RM Jr, Brown CC, Miller PJ, Afonso CL (2016) Effects of chicken interferon gamma on newcastle disease virus vaccine immunogenicity. PLoS ONE 11(7):e0159153

11. Gan L, Tian Y, Zhao Y, Xq S, Zhou W, Xia BB, Chen J, Wang ML, Zhao J (2019) Enhancing immunogenicity and protective efficacy of inactivated avian influenza H9N2 vaccine with recombinant chicken IFN- $\alpha$ in chicken. Vet Microbiol 234:77-82

12. Proietti E, Bracci L, Puzelli S, Di Pucchio T, Sestili P, De Vincenzi E, Venditti M, Capone I, Seif I, De Maeyer E, Tough D (2002) Type I IFN as a natural adjuvant for a protective immune response: lessons from the influenza vaccine model. J Immunol 169(1):375-383 
13. Egli A, Santer DM, O'Shea D, Tyrrell DL, Houghton M (2014) The impact of the interferon-lambda family on the innate and adaptive immune response to viral infections. Emerg Microbes Infect 3(1):1-12

14. Jewell NA, Cline T, Mertz SE, Smirnov SV, Flaño E, Schindler C, Grieves JL, Durbin RK, Kotenko SV, Durbin JE (2010) Lambda interferon is the predominant interferon induced by influenza A virus infection in vivo. J Virol 84(21):11515-11522

15. Dellgren C, Gad HH, Hamming O, Melchjorsen J, Hartmann R (2009) Human interferon- $\lambda 3$ is a potent member of the type III interferon family. Genes Immun 10(2):125-131

16. Bolen CR, Ding S, Robek MD, Kleinstein SH (2014) Dynamic expression profiling of type I and type III interferon-stimulated hepatocytes reveals a stable hierarchy of gene expression. Hepatol 59(4):1262-1272

17. Bartlett NW, Buttigieg K, Kotenko SV, Smith GL (2005) Murine interferon lambdas (type III interferons) exhibit potent antiviral activity in vivo in a poxvirus infection model. J Gen Virol 86(6):1589-1596

18. Ank N, West H, Bartholdy C, Eriksson K, Thomsen AR, Paludan SR (2006) Lambda interferon (IFN- $\lambda$ ), a type III IFN, is induced by viruses and IFNs and displays potent antiviral activity against select virus infections in vivo. J Virol 80(9):4501-4509

19. Zhou Y, Wang Z, Xu Y, Zhang Z, Hua R, Liu W, Jiang C, Chen Y, Yang W, Kong W (2017) Optimized DNA vaccine enhanced by adjuvant IL28B induces protective immune responses against herpes simplex virus type 2 in mice. Viral Immunol 30(8):601-614

20. Morrow MP, Pankhong P, Laddy DJ, Schoenly KA, Yan J, Cisper N, Weiner DB (2009) Comparative ability of IL-12 and IL-28B to regulate Treg populations and enhance adaptive cellular immunity. Blood 113(23):5868-5877

21. Ramakrishnan MA (2016) Determination of $50 \%$ endpoint titer using a simple formula. World J Virol 5(2):85-86

22. Motamedi-Sedeh F, Soleimanjahi H, Jalilian AR, Mahravani H, Shafaee K, Sotoodeh M, Taherkarami H, Jairani F (2015) Development of protective immunity against inactivated iranian isolate of foot-and-mouth disease virus type O/IRN/2007 using gamma rayirradiated vaccine on $\mathrm{BALB} / \mathrm{c}$ mice and guinea pigs. Intervirology 58(3):190-196

23. Szretter KJ, Balish AL, Katz JM (2006) Influenza: propagation, quantification, and storage. Curr Protoc Microbiol 3(1):15G-G21

24. Ge Q, Filip L, Bai A, Nguyen T, Eisen HN, Chen J (2004) Inhibition of influenza virus production in virus-infected mice by RNA interference. PNAS 101(23):8676-8681

25. Fotouhi F, Shaffifar M, Farahmand B, Shirian S, Saeidi M, Tabarraei A, Gorji A, Ghaemi A (2017) Adjuvant use of the NKT cell agonist alpha-galactosylceramide leads to enhancement of M2-based DNA vaccine immunogenicity and protective immunity against influenza A virus. Arch Virol 162(5):1251-1260

26. Naderi M, Saeedi A, Moradi A, Kleshadi M, Zolfaghari MR, Gorji A, Ghaemi A (2013) Interleukin-12 as a genetic adjuvant enhances hepatitis $C$ virus NS3 DNA vaccine immunogenicity. Virolo Sin 28(3):167-173

27. Hovden AO, Cox R, Haaheim L (2005) Whole influenza virus vaccine is more immunogenic than split influenza virus vaccine and induces primarily an $\mathrm{IgG} 2 \mathrm{a}$ response in $\mathrm{BALB} / \mathrm{c}$ mice. Scand $\mathrm{J}$ Immunol 62(1):36-44

28. Tumpey TM, Renshaw M, Clements JD, Katz JM (2001) Mucosal delivery of inactivated influenza vaccine induces B-cell-dependent heterosubtypic cross-protection against lethal influenza A H5N1 virus infection. J Virol 75(11):5141-5150

29. She YM, Cheng K, Farnsworth A, Li X, Cyr TD (2013) Surface modifications of influenza proteins upon virus inactivation by $\beta$-propiolactone. Proteomics 13(23-24):3537-3547

30. Gaidamakova EK, Myles IA, McDaniel DP, Fowler CJ, Valdez PA, Naik S, Gayen M, Gupta P, Sharma A, Glass PJ, Maheshwari RK (2012) Preserving immunogenicity of lethally irradiated viral and bacterial vaccine epitopes using a radio-protective Mn2+-Peptide complex from Deinococcus. Cell Host Microbe 12(1):117-124

31. Soema PC, Kompier R, Amorij JP, Kersten GF (2015) Current and next generation influenza vaccines: formulation and production strategies. Eur J Pharm Biopharm 1(94):251-263

32. Sommereyns C, Paul S, Staeheli P, Michiels T (2008) IFN-lambda (IFN-lambda) is expressed in a tissue-dependent fashion and primarily acts on epithelial cells in vivo. PLoS Pathog 4:e1000017

33. Gould VM, Francis JN, Anderson KJ, Georges B, Cope AV, Tregoning JS (2017) Nasal IgA provides protection against human influenza challenge in volunteers with low serum influenza antibody titre. Front Microbiol 8:900

34. Renegar KB, Small PA, Boykins LG, Wright PF (2004) Role of IgA versus $\mathrm{IgG}$ in the control of influenza viral infection in the murine respiratory tract. J Immunol 173(3):1978-1986

35. Rudin A, Riise GC, Holmgren J (1999) Antibody responses in the lower respiratory tract and male urogenital tract in humans after nasal and oral vaccination with cholera toxin B subunit. Infect Immun 67(6):2884-2890

36. Song JM, Wang BZ, Park KM, Van Rooijen N, Quan F-S, Kim MC, Jin HT, Pekosz A, Compans RW, Kang SM (2011) Influenza virus-like particles containing M2 induce broadly cross protective immunity. PLoS ONE 6(1):e14538

37. Lauder SN, Jones E, Smart K, Bloom A, Williams AS, Hindley JP, Ondondo B, Taylor PR, Clement M, Fielding C, Godkin AJ (2013) Interleukin-6 limits influenza-induced inflammation and protects against fatal lung pathology. Eur J Immunol 43(10):2613-2625

38. Yu X, Zhang X, Zhao B, Wang J, Zhu Z, Teng Z, Shao J, Shen J, Gao Y, Yuan Z, Wu F (2011) Intensive cytokine induction in pandemic H1N1 influenza virus infection accompanied by robust production of IL-10 and IL-6. PLoS ONE 6(12):e28680

39. Kaiser L, Fritz RS, Straus SE, Gubareva L, Hayden FG (2001) Symptom pathogenesis during acute influenza: interleukin-6 and other cytokine responses. J Med Virol 64(3):262-268

40. Gentile D, Doyle W, Whiteside T, Fireman P, Hayden FG, Skoner D (1998) Increased interleukin-6 levels in nasal lavage samples following experimental influenza A virus infection. Clin Diagn Lab Immunol 5(5):604-608

41. Fritz RS, Hayden FG, Calfee DP, Cass LM, Peng AW, Alvord WG, Strober W, Straus SE (1999) Nasal cytokine and chemokine responses in experimental influenza A virus infection: results of a placebo-controlled trial of intravenous zanamivir treatment. J Infect Dis 180(3):586-593

42. Van Reeth K, Van Gucht S, Pensaert M (2002) Correlations between lung proinflammatory cytokine levels, virus replication, and disease after swine influenza virus challenge of vaccination-immune pigs. Viral Immunol 15(4):583-594

43. Quan FS, Huang C, Compans RW, Kang SM (2007) Virus-like particle vaccine induces protective immunity against homologous and heterologous strains of influenza virus. J Virol 81(7):3514-3524

44. Sun K, Torres L, Metzger DW (2010) A detrimental effect of interleukin-10 on protective pulmonary humoral immunity during primary influenza A virus infection. J Virol 84(10):5007-5014

45. Sun J, Madan R, Karp CL, Braciale TJ (2009) Effector T cells control lung inflammation during acute influenza virus infection by producing IL-10. Nat Med 15(3):277-284

46. McKinstry KK, Strutt TM, Buck A, Curtis JD, Dibble JP, Huston G, Tighe M, Hamada H, Sell S, Dutton RW, Swain SL (2009) IL-10 deficiency unleashes an influenza-specific Th17 response and enhances survival against high-dose challenge. J Immunol 182(12):7353-7363

Publisher's Note Springer Nature remains neutral with regard to jurisdictional claims in published maps and institutional affiliations. 